[ entrevista ]

\title{
Entrevista com Antonio Arnoni Prado
}

Essa entrevista com Antonio Arnoni Prado, professor de Literatura Brasileira, da Universidade Estadual de Campinas, foi realizada após o encerramento do curso de pós-graduação, "Literatura e crítica literária na transição para o Modernismo 1890-1922" ministrado no primeiro semestre de 1999, a convite da área de Literatura Brasileira. Arnoni vem se destacando por suas pesquisas em torno do Pré-Modernismo: 1922: itinerário de uma falsa vanguarda [Brasiliense, 1983], Contos anarquistas: antologia da prosa libertária no Brasil (1901 - 1935) [Brasiliense, 1985 - com Francisco F. Hardman], Lima Barreto: o crítico e a crise [Martins Fontes, 1989]. Entre seus últimos trabalhos, é digno de nota $O$ espírito e a letra [Cia. das Letras, 1996] - tarefa a qual dedicou sete anos -, reunindo em dois volumes toda a crítica literária do historiador Sérgio Buarque de Holanda. Alguns desses autores e temas foram revisitados pelo professor Arnoni nesta conversa. 
No seu trabalho Lima Barreto: o crítico e a crise, publicado em 1976 e reelaborado em 1989, você procurou combinar análise literária com análise ideológica. De lá para cá, o que mudou no seu método crítico e também em relação à figura e à compreensão da obra de Lima Barreto?

Penso que continuo tentando combinar as duas visões no foco das minhas análises. Ainda acho que a experiência vivida primeiro com os seminários de Antonio Candido na USP e depois com a edição da crítica dispersa de Sérgio Buarque de Holanda - e aqui foram quase sete anos - segue me propondo essa espécie de busca simultânea e sem volta. O que mudou foi a minha compreensão da crítica e da história literária enquanto referência para o percurso das obras, dos autores e do contexto em que eles se cruzam. Nesse sentido, o que a ideologia resumia e aclarava sempre antes do texto, interferindo na seleção dos pontos de chegada, hoje se integra ao que posso chamar de busca paralela da ressonância crítica do processo literário tanto no tempo histórico quanto no hermenêutico. Assim, para retomar esse trabalho, hoje me parece que o Lima Barreto da crise (embora decisivo) talvez seja menos importante que o Lima Barreto da crítica, porque se o primeiro coube com folga na imagem militante que se tinha (e se construiu) dele, o segundo desborda da moldura e segue nos provocando em dimensões tão agudas quanto as de seu inconformismo social e político. Penso aqui no que se poderá avançar ainda em relação, por exemplo, ao crítico literário, ao admirador do teatro, ao inovador do texto jornalístico, para não falar do crítico das linguagens, que os intérpretes de outras áreas vêm às vezes simplificando com uma voracidade de dar medo. Isso alterou a visão que eu tinha tanto do escritor quanto do intelectual. O militante, que, a meu ver, encolheu-se na primeira leitura do tempo histórico, parece-me agora muito mais vivo quando visto na complexidade de seu tempo hermenêutico, apesar das tantas reduções que a sua obra vem sofrendo.

Arnoni, o seu interesse pelo Lima Barreto e, principalmente, pelo Pré-Modernismo surgiu durante os seminários com Antonio Candido. O que foram esses seminários e como seu interesse se voltou para esse período da Literatura Brasileira? Esses seminários marcaram a vida de toda uma geração. Quando prestei o exame para ser admitido nos seminários, havia somente cinco vagas para mais de sessenta candi- 
datos. Nessa época, além de Letras, cursava também Filosofia e Direito. Era um estudante profissional. E aí tem um caso curioso. Eu não estava pensando em fazer o seminário, mas um amigo meu insistia que eu deveria fazer. E foi ele mesmo que acabou fazendo a minha inscrição. No dia do exame, que começaria às 9 horas, acabei chegando atrasado, às $9 \mathrm{~h} 15$. Por causa disso, o Antonio Candido dizia que havia duas pessoas que se chegassem na hora não havia graça nenhuma: eu e o José Miguel Wisnik. Bom, mas voltando ao seminário, quando vi que tinha passado, eu nem acreditei. Isso foi em 1971.

\section{Como eram esses seminários?}

Lia-se o tempo todo. O Antonio Candido escolhia um assunto para cada aluno e passava as leituras. Por exemplo, numa segunda-feira, ele me pediu que apresentasse na quarta um seminário sobre Propp. Isso fazia parte de uma coisa que não sei se existe mais, que eram os cursos sobre as teorias críticas. Cada um de nós tinha que apresentar um autor. Com Candido, aprendi a ler um texto, a ler os problemas do texto, pois para ele um bom seminário é articulado a partir dos problemas que se encontra dentro do texto e não uma apresentação de toda a bibliografia sobre aquele autor. Ele queria saber o que o aluno achou sobre o tema. A gente não tinha como não se colocar perante os colegas. Além disso, o seminário era um momento em que todos se expunham. Nós sabíamos que cada um estava esperando os problemas apresentados pelo outro para poder

discutí-los e discutir os nossos. Por isso, não dava para furar com o grupo. Esse curso, segundo Candido revelou, era um pouco o desenho de um projeto que ele fez em 1972. A idéia dele era pedir um financiamento à Fapesp para estudarmos todo o Pré-Modernismo. Como estava todo mundo sem assunto de tese, ele iria propor os assuntos para cada um de nós: Lima Barreto, Graça Aranha, Augusto dos Anjos ou, na crítica, João Ribeiro. Ele pretendia assim fazer um levantamento de todas as fontes durante quatro anos, mas infelizmente nem todos aceitaram. Porém, eu acabei ficando com todo o PréModernismo. Quinze anos depois, numa conversa, Antonio Candido me disse que eu estava fazendo justamente o que ele havia proposto, pegando assunto por assunto do período. E este ficou sendo o meu tema. E em 2 de fevereiro de 1975, defendi meu mestrado sobre o Lima Barreto. 
O que você ressaltaria como traço importante do estudo do Pré-Modernismo? Não seria mais apropriado chamar a literatura pré-modernista de "literatura da vida republicana" sendo que este é o seu traço de união, referente aos dilemas da experiência de uma vida não tutelada?

A meu ver o que há de mais importante a ressaltar no chamado Pré-Modernismo é a profusão de suas dissonâncias. Avanço estético que, anunciado, não se configura, ou configura-se às vezes apenas enquanto programa. Ao mesmo tempo, subserviência aos modelos de fora, ainda que matizada pela figuração retórica do apego à pátria, colada ao esnobismo pelo desdém grã-fino a tudo que não fosse nosso. Virou moda, em toda parte, encontrar novidades e antecipações modernistas nos autores desse período, que entrariam aí como "pré" como se alguém nascesse para ser "pré" alguma coisa. O que importa assinalar no período, no entanto, é que o conjunto dessas dissonâncias continua vivo nos tempos de hoje, na atualidade do Brasil como um país em que a modernidade é também ela um efeito de retórica e de preconceitos. Isso, se você for ver, mudou muito pouco em relação ao que somos hoje. E desdobra a contraparte do Pré-Modernismo não para o Modernismo propriamente, como é hábito julgar, mas para o próprio sistema intelectual do país, se pensarmos no vivo esboço que dele nos traça um livro iluminador como Raízes do Brasil, por exemplo. Se você for ver, a derrota do grupo Zut! (tão mal descrita por Gonzaga Duque, em Mocidade morta, por exemplo), se por um lado confirma o fracasso de Lima Barreto ou o tom conciliador de um "modernista" como Graça Aranha, está toda no pessimismo retrospectivo da conferência de Mário de Andrade sobre as hesitações e as metas do movimento, em 1942. Sob este aspecto, chamar a literatura do período de "literatura da vida republicana" apesar de uma saída a pensar, pode ser uma redução, porque pelo menos até outubro de 1930 permanece o quadro institucional de normalidade republicana, muito embora o quadro literário tenha se modificado.

O Pré-Modernismo, segundo você disse, anuncia um avanço estético porém não consegue configurá-lo.

Eu acho que no Diário íntimo do Lima Barreto tem muito mais teoria e crítica literária do 
que em toda crítica que o circunda e que o excluiu. Nele, podemos encontrar o projeto de um escritor pensando como ele vai realizar a literatura dele, qual a relação entre o fato e o ato literário. Ele tinha consciência de que era preciso descartar a linguagem cristalizada da época para introduzir seu estilo pessoal. E o estilo é algo que não está decodificado pela linguagem circundante, feita e acabada. É como se ele dissesse que não queria ser literato, mas sim escritor. Acho que nesses escritos encontramos um ponto alto da consciência crítica daquele momento, mas algo que só pôde ser formalizado depois, pelo Mário de Andrade, já que Lima Barreto era incapaz de articular suas idéias de maneira ensaística. Ele simplesmente as jogava no papel. Mário vai poder dizer essas coisas no "Prefácio interessantíssimo" e no "A escrava que não é Isaura"

Mas quem aponta para essa consciência, contar o Brasil do ângulo da literatura, é o Sérgio Buarque de Holanda. Não seria mais o Brasil visto de cima, como até então se contava. Para o escritor, o país surge, agora, do contato com o mundo das pessoas e através de uma linguagem viva. O escritor vai misturar-se com essa linguagem, reelaborando assim suas imagens. Agora, só a crítica posterior explicou isso de modo claro e distintivo, uma linha crítica que vem de Antonio Candido para cá, passando por Alfredo Bosi e toda uma geração que hoje está afinando esse discurso. Digo isso, pois somente em 1959, 1960, é que nós vamos ter na literatura uma reflexão que põe em ordem as reflexões sobre o Brasil como totalidade pelo viés da especificidade dos problemas literários. E é por esse viés que eu também olho o Brasil e é através dessa linha de crítica que hoje falo de alguma coisa que aprendi

No seu primeiro trabalho a ênfase recaiu sobre um autor de esquerda, no segundo, 1922: itinerário de uma falsa vanguarda, o foco girava em torno da ideologia de direita. Hoje, dentro do quadro da Literatura Brasileira moderna e contemporânea, onde você encontraria ecos ou uma linha de continuidade desse pensamento conservador?

$\mathrm{Na}$ verdade, depois de ter estudado a trajetória marginalizada de Lima Barreto, eu me impus a tarefa de conhecer o universo ufanista e autoritário da direita que o excluía em nome de um projeto nacional por muitos anos hegemônico, como se sabe. O contraponto, para compensar uma parada tão indigesta, foi estudar - à esquerda do projeto 
de Lima Barreto - o avanço e a configuração ideológica da literatura e do teatro anarquistas. Dessas incursões, resultaram três livros (ao lado do Itinerário de uma falsa vanguarda, incluo os Contos anarquistas e o volume Libertários no Brasil) e alguns ensaios e artigos nos jornais e revistas. Quer dizer: o quadro das oposições ideológicas me foi imposto pela exclusão de Lima Barreto, e nada mais além disso. Dado que o contexto que se abre em 20 e pega fogo em 30 se alterou demais e, dado que algumas de suas raízes, depois do repique do golpe de 64, desaguaram no conjunto que rodou com a derrocada do muro de Berlim, creio que a polaridade, hoje, não me parece tão visível no horizonte. O processo atualmente é mais fundo, a começar pela capacidade impressionante que o pensamento conservador tem de se modernizar e mudar de lado. Tanto hoje quanto no passado, esse não é um fenômeno estranho à literatura. Basta ver que muitas vozes de radical discordância no passado hoje se afinam pelo filtro elitista dos que selecionam a experiência e fingem não se reconhecer na face triste que a realidade do Brasil de hoje nos revela a cada instante.

Durante seu curso na pós-graduação da USP, no ano passado, você traçou um quadro crítico que veio dos escritos dos pré-modernistas até os trabalhos de Mário de Andrade e Sérgio Buarque de Holanda. Você poderia comentar um pouco o roteiro e alguns aspectos dessa sua linha de pesquisa?

A idéia do curso foi trabalhar com autores do Pré-Modernismo, como Gonzaga Duque, Coelho Neto, Ioão do Rio, Lima Barreto e Graça Aranha. Eles entram no roteiro na medida em que cristalizam a consciência literária desse período. Se pensarmos em Mocidade morta, de Gonzaga Duque, percebemos que o foco do livro é o deslocamento da vanguarda, no caso, a das artes plásticas: a luta pela convergência nas relações entre crítica e produção pictórica. A mágoa dos "insubmissos" é que não havia ainda condições para a criação de uma pintura autenticamente nacional e não se valorizava quem se interessasse (como era o caso do grupo Zut!) por ela. O dado novo é que esse tema migra para a ficção, ficção escrita justamente por um crítico. Daí a meu ver o interesse do livro: mostrar como um ensaísta que está sentindo o isolamento dos jovens da sua geração, dá um tratamento ficcional a esse tema de crítica. A questão da onosarquia, que aparece como foco do pessimismo do romance, era ali uma resposta indignada da crítica 
a essa necessidade de buscar uma forma própria, com materiais próprios de uma arte própria, cuja criatividade, segundo Duque, foi abafada pela linhagem européia da Academia Imperial de Belas Artes. Tanto que muitos nomes da época desapareceram completamente, o que nos dá uma oportunidade muito viva para retomar a história desse tema e desses destinos. E depois, se pensarmos no desenvolvimento que o próprio Duque deu a sua obra ensaística posterior, podemos avaliar o quanto foi moderno nessa atitude que varia os ângulos e não perde de vista um tema que seria vital para a nossa cultura depois da Semana.

lá no romance A conquista, de Coelho Neto, a idéia foi comparar e realizar um balanço da geração que fez a Abolição. Claro que o foco, aí, é a história de uma geração consagrada narrada depois que os fatos ocorreram, com personagens por assim dizer heróicos, gente como Olavo Bilac, Aluísio Azevedo, Coelho Neto. Ou seja: uma literatura que conta a saga de uma conquista político-social pelo viés da ideologia dos literatos da boêmia dourada, voltada para Paris e para o estilo do realismo cosmopolita que imita Eça de Queirós, mas muito próxima do exílio dos "insubmissos" do grupo Zut! no que diz respeito aos preconceitos contra o próprio país. Tudo numa linguagem que encobre o Brasil real reclamando o tempo todo de sua modernização. O pessimismo dos excluídos de Gonzaga Duque em nada difere do otimismo dos eleitos de Coelho Neto. Em ambos a arte e a literatura entram como figurações abstratas em que a meta é o destino singular dos personagens em sua trajetória para se transformar em gigantes. A metáfora do balão do Patrocínio, pode ser um exemplo. Proclamada a Abolição, os heróis se desvencilham do povo a toda pressa e dão uma banana para as massas alvoroçadas nas ruas do Rio de laneiro. O vôo para Paris, no sonho dos libertadores, é também uma forma de exílio, numa época em que o escritor se profissionalizava e ingressava na Academia.

Entre os dois livros, assim, persiste um vazio que é tão forte na adversidade intelectual do excluído quanto na euforia artificial do boêmio em trânsito para a Academia. Essa preocupação acompanhou os demais tópicos do curso, já que tivemos em pauta toda uma atividade crítica divorciada da ficção, como é o caso de loão Ribeiro e a idéia de que não podíamos ter um estilo próprio porque não tínhamos um estilo nacional. Ou de um Nestor Vítor embevecido em Paris e lendo tudo na craveira dos simbolistas, numa espécie de hiato que é jogado depois para 22. Isso para não incluir as trajetórias em tudo opostas de João do Rio e de Lima Barreto, que estiveram no centro do nosso curso. 


\section{De que forma surgem esses dois escritores dentro dessa abordagem que você}

está fazendo?

João do Rio abre no Brasil o desfrute da cultura cosmopolita. Ele é um homem capaz de ler um ensaio de Oscar Wilde e tomar uma frase dali para fazer um conto. Ele modula a ficção com a consciência de que a ficção não é só invenção. É alguma coisa que está ligada à técnica, ao cinematógrafo e a uma série de coisas como o comércio mais bruto. Isso lembra a figura do homem-sanduíche, que ele mostra bebendo cerveja até se arrebentar, para fazer propaganda do produto. É uma questão brutal do ponto de vista de expressar essa idéia, mas como nenhum outro escritor de esquerda pegou. João do Rio mostra a destruição pela apropriação da força de trabalho. Isso, Antonio Candido assinalou em "Radicais de ocasião" Essa ficção ampliou muito o campo da literatura. O relato flagrante entra como gênero ao lado do conto dialogado, que era coisa absolutamente inovadora, como nota o Sérgio Buarque de Holanda, num dos artigos do primeiro volume de O espírito e a letra, pondo em crise o perfil da personagem tradicional do Naturalismo, quando o conto tinha uma hipótese a ser provada. Há contos do João do Rio nos quais a gente não sabe onde está o foco descritivo ou narrativo - é uma ambigüidade: pode ser uma parolagem, uma coisa vazia, mas no fundo é um retrato do cotidiano que retoma exatamente a crise do grande personagem do Realismo pós-Machado, quando já se pensa, no Brasil, que não é mais possível narrar uma história com começo, meio e fim. Quer dizer: a história contada como uma iluminação flagrante do fato. Mas esse é um sintoma à direita do sistema literário. À esquerda está Lima Barreto, através dele sabemos que a massa libertada com a abolição virou massa de manobra, que esses negros estão no subúrbio. Com ele, surge uma outra cara, uma outra realidade aparece na ficção brasileira.

\section{É neste ponto que seu curso deu uma virada para a crítica de 22, para a compreen- são de todo esse processo.}

Veja onde pára o curso. Ele pára em duas pontas. Uma ponta é a consciência crítica de que a ficção tem leis próprias e não tem leitores ou não tem procedimentos. Ou o que vem, vem de fora acabado, que é a questão que o Roberto Schwarz coloca sobre o ponto de vista não só formal, mas sobretudo do contexto. E na outra ponta, uma imagem de Brasil vinculada a pessoas que nós temos que saber quem são. Na passagem para 22. 
pode-se buscar em Mário de Andrade exatamente isso. O Sérgio Buarque e o Mário são os dois últimos momentos da nossa trajetória. Nós temos um historiador que quer ser escritor e que por alguma circunstância acabou se convertendo num dos maiores historiadores do Brasil e que tem uma noção de literatura que é absolutamente fundamental, porque é ele quem vai fazer uma radiografia do Modernismo, vinculando-o às fontes da modernidade literária na Europa. Portanto, alguém que conhece a cena literária, mas que não se satisfaz com ela. Esse é um ponto intrigante que enfatizei muito no curso: por que o Sérgio, que foi um militante do Modernismo (inclusive com escritos ficcionais), rompe com 22, joga tudo para o alto e vai embora? Exatamente porque não concorda com o que Raymundo Faoro chamou de "modernistas da ordem" Os "modernistas da ordem" eram seus amigos diletos, aqueles que o levaram para o coração de 22. ou seja, o Menotti Del Picchia e o Guilherme de Almeida, com os quais ele viu nascer a revista Klaxon. A modernidade no Brasil, para o Sérgio, estava na América Latina, no salto para o contexto latino-americano. Ele percebeu que havia um buraco, então, ele rompe. E quando retorna, traz Raízes do Brasil. Quer dizer, Raízes do Brasil, até onde eu enxergo, é uma resposta intelectual dele para o projeto renovador que o levou para o movimento de 22

\section{E qual era esse projeto?}

Primeiro, passar pelas condições que nos impunham uma forma de pensar o Brasil. Não era simplesmente romper com a linguagem cristalizada do Parnasianismo, da ordem imposta pelo Naturalismo, pelo Neo-Naturalismo, mas atacar - no fundo - essa visão bacharelesca, a visão do bovarismo, da civilização que vai pelo contorno e pelas margens, que não mergulha no coração desconhecido da nossa matéria bruta.

\section{E que relação você encontra entre o Sérgio Buarque e o Mário de Andrade?}

Trata-se de uma questão muito difícil, mas pode-se falar numa relação de inventividade de pesquisa na interpretação dessa matéria bruta. E, sobretudo, uma vocação inédita nos dois para o olhar extenso que intui a multiplicidade de linguagens que conviviam no substrato da nossa cultura. Mário abriu o projeto e fugiu o quanto pôde das interpretações. Nele o abismo era constante e sempre provisório. Lembremos que é um dos 
nossos maiores poetas. Sérgio abriu para a síntese e a interpretação numa espécie de diálogo complementar. Tenho a impressão que a obra de Antonio Candido é uma síntese feliz e indispensável no intervalo entre as duas pontas.

Nesse ponto, Arnoni, surge o seu atual projeto. Em que estágio se encontra esse seu trabalho sobre os críticos fundadores da reflexão sobre a realidade brasileira (Mário de Andrade, Sérgio Buarque de Holanda e Antonio Candido)?

Ele ainda está muito cru. Mas, a meu ver, Sérgio Buarque e Antonio Candido criam uma nova perspectiva para a nossa história literária. Candido chamou o Sérgio de "meu mestre" juntamente com o Caio Prado Jr. e o Gilberto Freyre. Sérgio ampliou a noção do contexto sem perder a especificidade da linguagem literária. É uma coisa raríssima no Brasil alguém falar do contexto tendo consciência de que a forma que o engendra, significa por si mesma. Muita coisa foi retomada depois por Antonio Candido. De qualquer maneira, há impressão de que Mário e Sérgio se desvestem para encontrar um termo mais ou menos comum: o abismo na escuridão das origens ou a colonização sem raízes no coração da colônia. E Antonio Candido - essa é a minha hipótese - dá uma resposta para isso. Ele transcende os dois pois, tem um conhecimento das relações entre literatura e sociedade, só equiparável ao do Sérgio. Mário, talvez, por ser um artista, não consegue a síntese alcançada por Candido. Ele não arrisca tanto para o lado político, mesmo nos momentos mais candentes da luta ideológica no Brasil. Acho que hoje é preciso ler toda a obra de Mário e de Sérgio, inclusive passando pelo João Luís Lafetá e pelo rebate que Roberto Schwarz faz do Antonio Candido e, só então, conferir um sentido mais amplo a tudo isso. A minha experiência pessoal - foram oito anos de pesquisa -, me obriga a dar uma resposta perante meus alunos e meus amigos.

\section{Qual o seu objetivo nesse projeto?}

A minha pretensão está longe de explicar a obra de Antonio Candido. Trata-se apenas de armar uma relação entre textos críticos. Há um caminho literário entre o Sérgio Buarque e o Antonio Candido, inclusive no despojamento de estilo, já que o Sérgio é claramente mais rebuscado. Nesse ponto, há uma relação séria para compreender, digamos, a função da crítica no Brasil que joga, muito claramente, entre a consciência da elabo- 
ração e a noção de texto, como saída. Esse critério é bom como análise, mas o texto pede uma saída. E esses críticos oferecem uma resposta.

Ao organizar O espírito e a letra, reunindo estudos críticos de Sérgio Buarque de Holanda, você enfatiza a idéia de uma "recriação crítica", a partir da qual poderíamos considerar que as contribuições mais importantes de Sérgio estariam nos ensaios em que ele discute as questões ligadas à linguagem poética. Como avaliar a contribuição de Sérgio no que se refere à relação poesia e crítica?

Acho que a contribuição crítica de Sérgio Buarque de Holanda em relação à poesia do Modernismo não foi ainda avaliada. Sob certo aspecto, ela contextualiza as raízes estéticas do movimento na mesma proporção em que a crítica de Antonio Candido define todo um quadro de referência sócio-cultural para o processo da nossa literatura. A partir de Sérgio, a atividade poética não se desvincula da consciência crítica do texto e talvez esse seu lado não tenha sido ainda suficientemente discutido. Ao dialogar, por exemplo, com a geração de 45, reconheceu em João Cabral a autonomia da linguagem, mas recusou-se a aceitar a paragem na forma como último estágio no vôo do poeta. Tanto valorizou a pesquisa que discordou em mais de uma ocasião, e publicamente, de alguns poetas de 45, sugerindo que fossem além das conquistas de 22, um avanço que a seu ver não admitia mais retrocessos como a volta ao soneto ou à quadra rimada. Pesquisa, no entanto, que, segundo ele, precisava ir além e ampliar as tensões do ser e da vida no itinerário difuso das palavras e das coisas. Ao desenho vazio e preciso do texto corresponde sempre - para Sérgio - o denso intervalo da expectativa crítica que pulsa em qualquer manifestação da vida inteligente. Daí a presença viva do crítico sempre mergulhado nas chaves culturais da poesia e da história literária. Para Sérgio Buarque de Holanda criticar um texto era recompor, no tempo hermenêutico, a própria experiência intelectual de sua construção/invenção no tempo histórico.

Para Sérgio Buarque de Holanda, a relação entre crítica e história só se justifica pela ausência de um "historicismo crítico" e de um "absolutismo histórico" Diante dessa afirmação, como considerar a crítica, hoje, nas suas relações com a pesquisa histórica? 
Ao distinguir, como você bem diz, "historicismo crítico" e "absolutismo histórico" Sérgio só quis nos mostrar o erro dos que insistem em separar a crítica da história como territórios que se excluem. Para ele, o crítico e o historiador necessariamente se encontram no sentimento de que "as expressões de cultura são essencialmente mutáveis e não se convertem sem violência em normas adequadas para todos e para sempre" 10 espírito e a letra). Daí a improcedência do método fechado de leitura que não vem do texto para a vida ou vai da vida para o texto sem a mediação das circunstâncias que se cruzam no momento da elaboração da obra. A articulação de um crítico como Sérgio se dá, como mostrou Antonio Candido, não com a convenção literária ou retórica, mas com todo um ciclo de civilização que a circunscreve. O lado extraordinário de uma perspectiva como esta é que todas as chaves de leitura são simultâneas e atuais na mobilização hermenêutica de um texto, da incursão biográfica à análise sistemática da ordem lógica na articulação das palavras. Quer dizer, se numa ponta Homero dialoga com Guimarães Rosa, na outra, Vico e Gustave Lanson podem complementar uma lacuna de Lacan ou mesmo de Georg Lukács. Aqui a intemporalidade do texto legitima a persistência da sua própria atualidade.

Arnoni, por que a prosa simbolista é objeto esquecido ou desprezado pela crítica? Em que medida essa prosa - tomando como exemplo Cruz e Sousa, na poesia, e Gonzaga Duque, no romance - poderia despertar o interesse, justamente por ser um objeto "falhado"? Não há certa vantagem no estudo do objeto inacabado no sentido da apreensão estética dos impasses sociais de determinado período? E, aproveitando, a que você atribui o abandono do cultivo do poema em prosa no Brasil, já que, por exemplo, na França, ele teve um papel fundamental no advento do verso livre e da modernidade em literatura?

Não foi só a prosa simbolista, mas o Simbolismo como um todo, que não recebeu da crítica toda a atenção que merecia, ressalvando - é claro - alguns excelentes trabalhos de que dispomos sobre o tema. A verdade é que o Simbolismo parece não ter tido por aqui a importância que assumiu na Europa, onde se diluiu num decadentismo feroz e corrosivo, com fortes conseqüências no projeto das vanguardas, como a gente sabe. Mas a dobra decadentista do simbolismo brasileiro, como vimos no nosso curso, é cheia de 
sugestões e merece ser integrada não apenas no contexto ideológico da transformação do papel do escritor e da literatura nesse período, como também na modulação de uma outra subjetividade que põe em crise a rigidez do metro parnasiano, desorganizando os limites mínimos do gênero. E é justamente essa impressão de objeto "falhado" que dá à prosa simbolista uma dimensão de não-lugar que costura a multiplicidade de vozes no narrador-poeta-cronista já longe da torre de marfim, mas ao mesmo tempo um outsider no mundo dos maquinismos e das transformações do cotidiano abertas com o novo século. Longe de se impor como um gênero, ela não tem lugar e modo para acontecer, por isso desmancha limites, absorvida com a ampliação do foco literário do poema-contocrônica, onde passa a caber de tudo. Por isso eu talvez discorde de que o poema em prosa "tenha sido esquecido pelos modernistas" como você propõe. A meu ver - alterada é claro a perspectiva do tom - no Modernismo ele emigrou para a crônica, um gênero de vozes bem nossas que se articulam em falsete, iluminadas pelo senso errático do eu lírico, agora empurrado para a contigüidade do histórico. Quando não, ele permanece onde sempre esteve. Está bem vivo, por exemplo, nos excertos de melancolia que recortam a prosa de um Murilo Mendes ou nas reminiscências que iluminam retratos na escrita circunstancial de um Manuel Bandeira. E (como! e quanto!) nas digressões sentimentais presentes na intemporalidade das lembranças de um narrador como Pedro Nava.

\section{Você acha que estamos nos afastando de toda uma tradição tanto na crítica quan- to na criação literária?}

Acho fundamental o diálogo com a tradição. Por exemplo, a ficção brasileira contemporânea não está seguindo essa trilha. Não sei se o escritor hoje está preocupado em repensar a tradição e formular uma nova síntese criativa. Essa é uma questão em aberto. Até que ponto esse caos não é uma amputação de alguma coisa que perdemos na evolução social de nossa história recente? Algo que a ficção e a poesia já trabalharam e que. agora, parece uma linha de pesquisa estética abandonada. Essa é uma tarefa nossa, ou seja, reestabelecer os diálogos... Outro dia, conversando com o Alfredo Bosi, ele recordava que era comum ir às livrarias com o prof. Ítalo Betarello, no centro de São Paulo. Ele pegava o Bosi pelo braço: "você precisa comprar esse livro" Ele ensinava a comprar os livros! Quer dizer, alunos e professores tinham uma vivência para além da sala de aula. 
E o Bosi me disse que lamenta o aluno ter perdido essa convivência com os professores no âmbito da própria universidade, a seu ver, indispensável à formação intelectual.

Participaram dessa entrevista Augusto Massi, Eliane Jacqueline Mattalia, Heitor Ferraz, Leila V. B. Gouvêa, Luiz Roncari, Salete T. A. Silva e Simone R. Rufinoni.

Teresa n:1

1. sem. 2000

pp. 124 a 137 